\title{
Modern automobile vehicle repair practices in micro, small and medium scale garages in Ghana
}

\author{
Akpakpavi Michael \\ Mechanical Engineering Department, Accra Polytechnic, Accra, Ghana
}

Email address:

micakpakpavi@yahoo.com

To cite this article:

Akpakpavi Michael. Modern Automobile Vehicle Repair Practices in Micro, Small and Medium Scale Garages in Ghana. International Journal of Science, Technology and Society. Vol. 2, No. 6, 2014, pp. 216-222. doi: 10.11648/j.ijsts.20140206.19

\begin{abstract}
This paper assesses the modern automobile vehicle repair and maintenance practices in the micro, small and medium scale garages in Ghana. In the study, the various vehicle repair and maintenance practices were investigated using a questionnaire administered on vehicle repair garages in the country. In addition, some amount of data was generated through personal observations and informal discussions. The survey revealed that a large number of the auto-mechanics in the garages in the country have considerable years of auto repair working experience, but lack the ability to inspect and repair modern automobile vehicles due to low educational and technical levels. The auto mechanics also lack the ability to identify and use modern diagnostic equipments, manufacturers' manuals, computers and internet which have characterized modern vehicle repairs, in their repair practices. They also lack adequate tools, equipments and other logistical supports. To enhance modern vehicle repair practices in the country, training institutions and organizations such as the universities, polytechnics, the Ghana Institution of Engineers, Gratis Foundation, National Board for Small Scale Industries (NBSSI), the government and so on, should extend assistance particularly in the form of education, training and equipments to these local garages. This is to enable them remain in business and prevent garage closures due to their inability to repair modern automobile vehicles.
\end{abstract}

Keywords: Ghana, Modern Automobile Vehicles, Repair, Practices, Garages

\section{Introduction}

The local automobile repair and maintenance garages in Ghana are essentially classified as micro, small and medium scale garages. These designations are based on staff strength. The micro garages employ up to 5 employees with fixed assets (excluding land and building) not exceeding the value of $\$ 10,000$; small garages are those employing between 6 and 29 employees or having fixed assets excluding land and building not exceeding $\$ 100,000$; medium garages employ between 30 and 99 employees with fixed assets of up to $\$ 1 \mathrm{~m}$ [1]. The local garages can be further grouped into urban and rural. Automobile vehicle garages essential helps to service and maintain the vehicles.

The use of automobile vehicles on our roads plays a key role in road transportation system. In Ghana where land transport is largely in use compared to water, air as well as other modes of transportation, the use of automobile vehicles, either diesel or petrol driven is predominant. However, the vehicles cannot remain new forever. A continuous use of the vehicles results in their general wear, tear and breakdowns; and as the parts breakdown and wear out, so, must be maintained [2]. When something is maintained, the idea is to keep it in a good and functional state. Vehicle maintenance refers to a practice where an automobile is serviced on a regular basis to prevent a major breakdown or the need for major repair. Examples of the type of auto services that may be sought for maintenance purposes include changing the oil, changing the spark plugs, and rotating the tires. It is believed that an automobile vehicle will last longer and operate better if a person adheres to the vehicle maintenance schedule [3].

Modern automobile are a blend of $20^{\text {th }}$ century and $21^{\text {st }}$ century technology. The designs of modern vehicles have advanced to a very sophisticated level. Unlike the old mechanical operated vehicle systems, the modern vehicles are being operated and controlled by computerized electrical sensors. Indeed, almost every other function within the engine is controlled by an onboard computer [4]. Moreover, common to majority of the new trend cars is the brain box and other electronic gadgets that sense instant faults in the vehicle and immediately notifies the driver through the dashboard display. The modern trend of mechanical services therefore requires the use of more complex and highly technological 
specialty diagnostic equipment to analyze vehicle faults for repair and service. To ensure this for efficiency, safety, comfort, style and so on, competent professional hands are required [5]. As vehicle technology and maintenance processes are advancing, the problems facing automobile garages in the country have rather compounded.

Currently, it is a common knowledge that a large proportion of the auto mechanics, both the experienced and trainees, of the local garages in the country find it extremely difficult to diagnose, repair and maintain modern cars. Indeed, this has worked to the effect that most of the local garages in the country, especial the micro and small ones are now currently out of business. The problems faced by the local garages in country as far as the repair and maintenance of modern cars are concerned could be attribute to reasons such as, low technical educational levels of auto mechanics, high cost of operations, lack of diagnostic machines, waste of time in detecting faults, damage to engines without the use of diagnostic machines in detecting faults, lack of appropriate maintenance practices, loss of customers and so on. A visit to some micro and small garages in the industrial estates in Ghana including, 'Kokompe' in Accra, 'Suame Magazine' in Kumasi and Tema reveals that vehicle diagnosing, repair and maintenance activities are carried out without sound and state-of-the- art maintenance practices.

This paper seeks to provide insight into modern automobile vehicle repair and maintenance practices in the micro, small and medium scale garages in Ghana. It is the researchers believe that this paper would help bring to the fore the challenges and prospects of modern automobile vehicle repair and maintenance practices in the country.

\section{Material and Method}

Two different types of survey were used to gather data: structured questionnaires and face-to-face interviews. The questionnaires were administered to selected automobile vehicle repair garages in Kumasi, Accra, and Tema metropolis. The survey was confined to these places because most industrial activities are concentrated there [6]. Indeed, this finding is still the same now [7]. Also, the three centers mentioned are all urban areas. Hence, it was taught that the views of the respondents from these centers would adequately represent the whole population. In all, 100 small and medium scale garages in the country were visited. Data on vehicle maintenance practices and procedures in the local garages in the country such as: quality control, available vehicle repair and maintenance tools and equipment, the use of engineering drawing, use of computer systems for vehicle faults diagnosing and repairs, technical qualifications of mechanics, training of mechanics, and other related issues were captured.

The response rate of the questionnaires was greater than $80 \%$. Apart from questionnaires being the main research instrument used, observations and discussions were also used to some extent in gathering the relevant data. Where applicable, the data collected was analyzed using bar charts and pie charts and the results were summarized with appropriate conclusions and recommendations made from it.

\section{Results and Discussion}

\section{A. Working Experience and Level of Technical Training}

With regards to the number of years of working experience of the automotive mechanics in the selected automobile vehicle garages in the country, out of the $80 \%$ response rate, about $60 \%$ have had more than 10 years working experience, $35 \%$ had between $6-10$ years working experience, whiles only $5 \%$ had between 1-5 years automotive maintenance working experience. Moreover, the levels of education as indicated by the auto mechanics in the selected automobile vehicle garages includes: 8\% have had Ordinary City and Guilds Certificates, $13 \%$ Senior Secondary School Certificates (SSSCE), 23\% had Basic Education/Middle School Leaving Certificates (BECE), $12 \%$ primary school, while $44 \%$ possessed other qualifications in the form of apprenticeship. Fig. 1 and 2 show these findings.

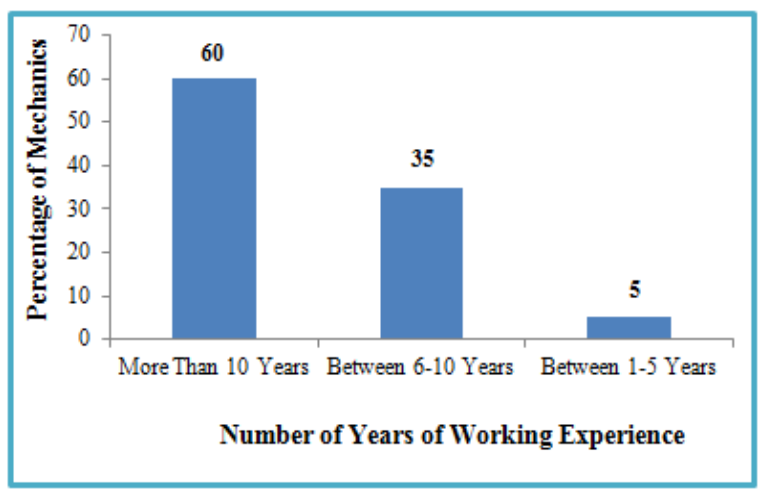

Fig. 1. Number of Years of Working Experience of mechanics

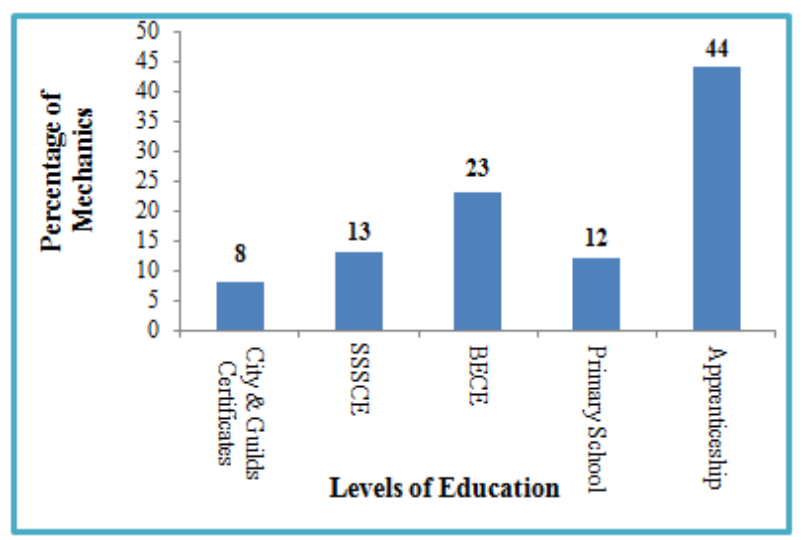

Fig. 2. Educational Levels of Mechanics

As shown in fig. 1 a large majority of the auto mechanics in the country have over 10 years of working experience, indicating that they possess enough experience in repair and maintenance of automobile vehicles. However, despite their vast experience in automobile repair practices, most of the mechanics in the country find it difficult to diagnose and repair modern trends of automobile vehicles, especially modern electronic engines. The mechanics inability to repair and maintain modern automobile vehicles could be largely 
attributed to their low levels of education. As pictured in fig. 2, over $75 \%$ of auto mechanics in the country possess educational levels way below secondary school levels. This low level of education of the auto mechanics in the country has caused a major setback in that most of them are ignorant and not quite familiar with the advancing technological know-how of the trade. Some of them cannot read and write, and so find it difficult referring to instruction manuals, which has rather characterize modern auto repair practices. Again, the mechanics low levels of education have resulted in situation where most of them find it extremely difficult identifying the components of modern electronic engines by their technical names correctly. Table 1 illustrates some of the 'adaptive' local names of the modern electronic engine components by the mechanics in the country.

Table 1. Adaptive local names of electronic engine components by mechanics in the country

Components As Locally Known
Accelerator
Temperature switch
Control board
Key switch
Carburetor seat
Oil switch

Oil switch
Correct Technical Names of Components

Accelerator potentiometer

Temperature sensor

Electronic control unit

Ignition unit

Air mass meter

Oil level sensor

Source: Authors' Fieldwork, 2014

Moreover, from observations, apart from possessing low educational levels, a very large number of the auto mechanics in the country do not have knowledge in basic Physics, Mathematics and computer skills which are pre-requisites for repairing modern automobile vehicles.

However, modern practices of automobile vehicle faults diagnosis, repair and maintenance require highly trained mechanics. The job of an auto mechanic has become increasingly specialized in the 21 st century. With the rapid advancement in technology, the mechanic's job has evolved from purely mechanical, to include electronic technology. Because vehicles today possess complex computer and electronic systems, mechanics need to have a broader base of knowledge than in the past. Fully skilled modern automotive repairers must have good reading ability and basic mathematics and computer skills. Restoring automobiles to their original form, state and working condition requires mechanics to follow instructions and diagrams in technical manuals in order to make precise three-dimensional measurements of the position of one body section relative to another as well as diagnose and repair the vehicles [8]. The Internet is even spreading to mechanics, with certified mechanics providing advice online. Mechanics themselves now regularly use the Internet for information to help them in diagnosing and/or repairing vehicles. Service manuals for vehicles have become significantly less prevalent with computers that are connected to the Internet taking their position [9].

It is therefore incumbent on the auto-mechanics in the country to keep updating and upgrading their technical competencies and skills in order to enable them to continually develop the capability to inspect and repair modern automobiles without being kicked out of business due to technological advancements. The non formal division of the Ghana Education Service, the Institute of Adult Education and other similar organizations in the country organize programs that seek to assist illiterate adults to acquire the basic skills of reading, writing and arithmetic as well as computer skills. The mechanics in the micro and small scale garages in the country should take advantage of these and other similar programs and offer themselves for functional literacy training.

B. Availability of Adequate tools and equipments in the garages

On the issue of whether the garages in the country have adequate tools and equipments to enable them conveniently and speedily inspect and repair modern automobile vehicles, $80 \%$ of the small and medium scale garages in the country did not have enough tools and equipments, whilst about $20 \%$ had almost all the required tools and equipments to work with. Fig. 3 depicts this finding in percentage terms.

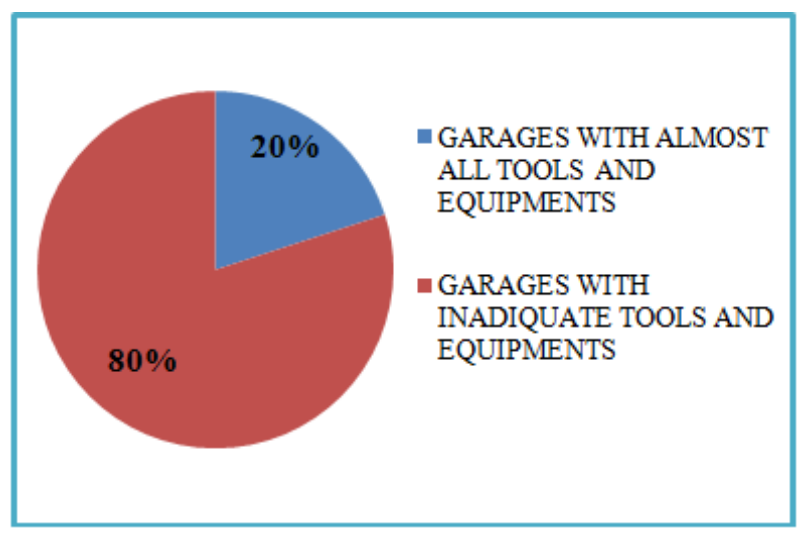

Fig. 3. Availability of adequate Tools and Equipments in garages

As pictured above, more than $80 \%$ of the small and medium scale garages in the country do not have adequate tools and materials to work with. Personal discussions with the mechanics of these local garages reveals that apart from not having most of the required basic tools and equipments, the garages also do not have modern vehicle diagnostic equipments such as: oscilloscope, scan tool, diagnostic code readers, portable data link, computer diagnostic testers, exhaust gas analyzers, computers, internet connectivity, etc. From personal interview with the garages, most of the mechanics also lack basic working knowledge and application of these diagnostic equipments. Not surprisingly, they are currently finding it extremely difficult to inspect, repair and 
maintain current trend of automobile vehicles leading to gradual job losses.

The job of an auto mechanic has become increasingly specialized in the 21 st century. Until the 1960 s, all one needed was a good wrench set, a strong pair of pliers and a couple of sizes of screwdrivers and one could repair most cars. Modern cars are much more evolved, with hundreds of computer chips and solid state electronic parts. It requires specialized equipment to diagnose problems with these sophisticated electronic devices [9]. With the electronic diagnostic equipments, mechanics compare the data produced by the diagnostic equipment to the standards provided by the manufacturer. This enables the mechanics to accurately diagnose problems based on the latest information downloaded from manufacturer databases. Hence, auto mechanics today have to learn how to use modern electronic diagnostic equipment as well as all of the traditional tools of the trade [10].

To remain competitive in the globalize market, and to continue to function effectively in this 21 st century, the garages in this country need to stock the relevant modern and even ultra modern tools and equipment necessary for modern car repairs. They should also endeavor to update and upgrade their technical competencies on the usage and correct working functioning of modern automobile vehicle repair tools and equipments. Indeed, this is the only way the small and medium scale garages in the country can survive.

c. Land and other infrastructure Ownership by Garages

Acquisition of land for establishment of garages in this country has been a major problem. On the issue of land ownership and acquisition, out of the $80 \%$ response rate, about $75 \%$ of the garages rented the land, $20 \%$ leased the land, while only $5 \%$ bought and own the land for their garages. This finding is as illustrated in fig. 4.

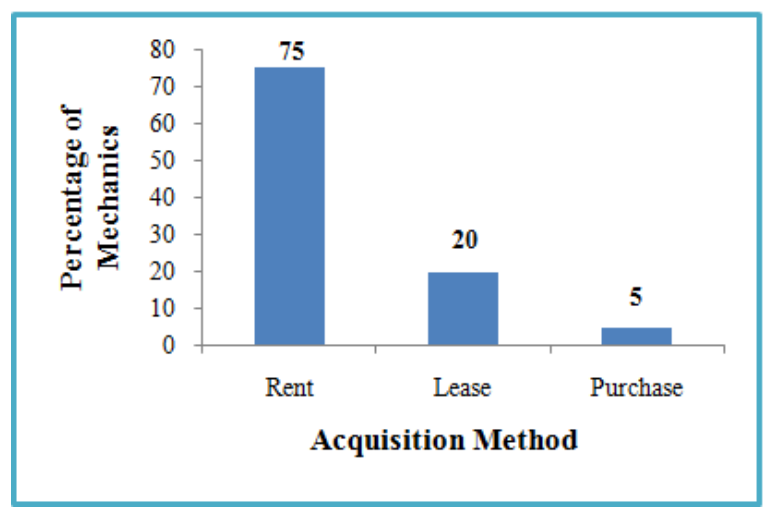

Fig. 4. Land Acquisition Method

As depicted in fig. 4, over $95 \%$ of the garages acquired their lands through rent and lease. An informal discussion with the garages reveals that, they rent and lease the lands simply because the lands are not available for sale in strategic areas where location of garages can be lucrative and the few ones that are available are very expensive particularly in the big towns and cities of the country including Accra, Kumasi, Tema and Takoradi. Again, informal interviews reveal that most of the landlords/owners have not developed cordial relationship with the garage owners in the country. According to the garage owners, the landlords intermittently visit them with verbal and written notices of threats and ejection. This rather makes them continually unhappy.

Moreover, knowing that they acquired the lands through lease and rent means that the garage managers have fixed periods and years to operate the garages at their locations. The garage owners in the country, therefore, finds it extremely difficult to access bank loans to expand, resource and retool their various garages. This has resulted in low status of automobile vehicle repair and maintenance practices in the various garages in the country.

To assist the garage owners in this regard, the government should come up with clear cut policies that will help foster cordial relationships between garage owners and landlords. Where necessary, the landlords and garage owners should use a memorandum of understanding to clearly define their relationships.

\section{Capital and Infrastructure Investments}

On the above issue, out of the $80 \%$ response rate by the micro, small and medium garages in the country, about $60 \%$ had a working capital (that is, excluding land and building), of less than and up to $\mathrm{GHC} 17,500.00 ; 23 \%$ had operated between GHC17,850.00 and GHC35,000.00; 10\% had operated between GHC38,500.00 and GHC105,000.00; 5\% did operate between $\mathrm{GHC} 108,500.00$ and $\mathrm{GHC} 175,000.00$ whilst only $2 \%$ had a working capital between GHC178,500.00 and GHC455,000.00, where 1USD $\approx$ GHC3.5 (GHC, Ghanaian Cedi). This finding is as depicted in fig. 5 .

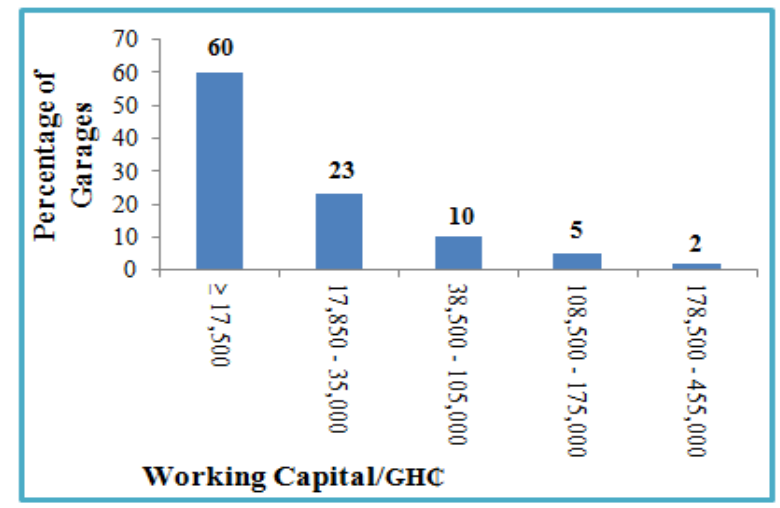

Fig. 5. Working Capital Investment in Garages

As illustrated in fig. 5, over $83 \%$ of the garage owners in the country started operating their garages with working capital way below GHC35,000 (that is, \$10,000). This implies that most of the auto repair garages in the country are of low standards. As a result of low capital investments, many garage businesses in the country are unsuccessful since they have not been able to establish themselves as trustworthy and dependable vehicle service providers. Most of them do not find it a good idea to offer warranties to their customers to ensure they always return for back jobs should there be problems with their repairs and services. Indeed, many of the garages in the country can best be described as oil changing 
centers. A large percentage of them use tools and infrastructures of low quality because they cannot afford the high quality ones that enhance proper fitting required. Engines are removed manually instead of using crane or hydraulic lift, and so on.

As illustrated in fig. 3, a good number of the garages in the country do not have adequate tools while the few ones that appear to have fairly adequate tools have such tools characterized with sub-standard attributes. The results are stress and consequent damage to auto parts. Moreover, most of the garages in the country are currently working in the informal economy. Few garages are registered and most are low-technology small-scale, family-based enterprises, many of which have difficulty accessing capital and wider markets All characteristics of the informal sector [12]. Similarly, much of the employment in the garages is informal with work carried out by auto technicians on their own account or with no written contract and no employment benefits or legal protection. Health and safety standards and other conditions of employment are generally low.

However, in developed countries such as the USA, Germany, China and the rest, heavy capital investments are made in vehicle automobile garages to ensure that they establish reputable service garages that are competitive, and safety practices are observed [15]. Again, most of the garages in these developed countries are operated formally and the necessary documentations and registrations are done even with insurance companies. These garages therefore are able to access capital and wider markets, and are also able to easily win international contracts [10].

Indeed, many of the garages in the country have a precarious existence with few buffers between themselves and poverty in the event of ill-health, adverse economic conditions or other misfortunes. To this end, it can be pointed out categorically that, as a result of low capital investments, most of the garages in the country are not able to generate enough income as they should. It is therefore incumbent on the owners of the garages in the country to make some additional capital investments in their garages to ensure that they establish garages with international reputes that will continually win the attraction and admiration of their customers. The government, banks, as well as other corporate organizations should assist these local small and medium scale garages to enable them procure the necessary and relevant modern diagnostic tools and equipment for their operations. Individuals can also assist by buying shares and equities in these small enterprises.

E. Vehicles Faults Diagnoses and Repair Practices by Garages

With regard to the approach adapted and adopted by the garages in the country in diagnosing and repairing faults on modern automobile vehicles, out of the $80 \%$ response rate, about $74 \%$ used the 'trial and Error' methods whilst $26 \%$ had used computer diagnostic machines and equipments in diagnosing faults on automobile vehicles. Fig. 6 depicts this finding.

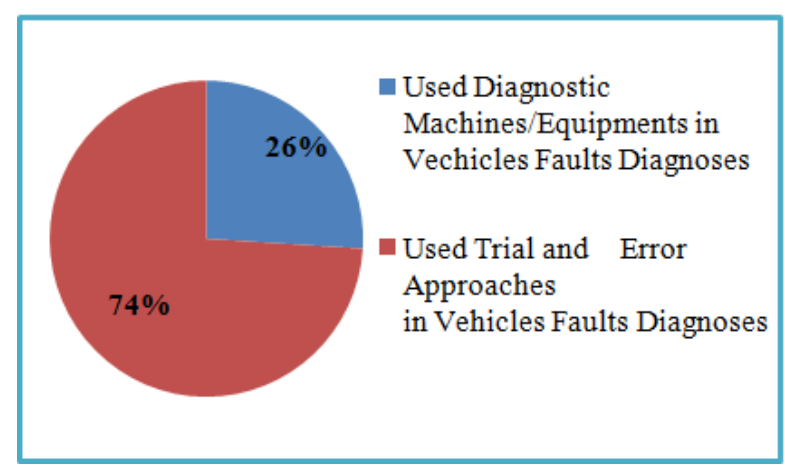

Fig. 6. Methods of vehicles faults diagnose by local garages

As shown in fig.6, a large proportion of the garages in the country adapts and adopts the use of 'trial and error' methods in diagnosing and repairing modern automobile vehicles faults. Hence, the application of new automobile technology to diagnosis of vehicle faults in most of these small and medium garages in the country is largely non-existent. The main reasons for this are: lack of exposure and basic knowledge of ICT skills by operators and inadequate facilities availability where mechanics can learn ICT and auto diagnosis skills. One of the biggest challenges for the local garages is the increasing ICT-driven entry barrier in the global automobile industry which manually-based practices of the current small and medium garages in the country cannot keep pace with. This technological barrier affects not only the auto mechanics, but also vehicle manufacturers, since customers are unable to secure quality support and servicing for modern vehicles. This leads to tarnishing of many vehicle brands, and creates an obstacle to newer vehicles entering the growing market in Ghana [11-12]. Also, the trial and error methods of vehicle diagnosis adopted by particularly the micro and small garages in the country tend to render them rather ineffective since they spend a lot of time trying to diagnose faults on vehicles which they never succeed in doing. They rather end up causing severe damages to modern engines with eventual high cost of operation and customer loss.

However, Vehicle electronics continue to get more complex, thus, making it harder to find faults. As a result, a very large majority of garages worldwide have resolve to extensive usage of wide verities of automotive diagnostic equipments and tools in their modern automobile repair and maintenance practices [13-14]. Indeed, even though the acquisition of these modern vehicle diagnostic equipments requires substantial capital investments, it is imperative that the small and medium garages in the country are updated and upgraded with these modern diagnostic equipments. This will not only assist them in repairing and maintaining the modern vehicles on the roads, but will also generally boost the transportation industry in the country.

\section{F. Training and Re-training}

On the issue of training and re-training of auto-mechanics in the country, out of the $80 \%$ response rate, only $36 \%$ did it, whilst $64 \%$ had not done it. This is illustrated in fig. 7 . 


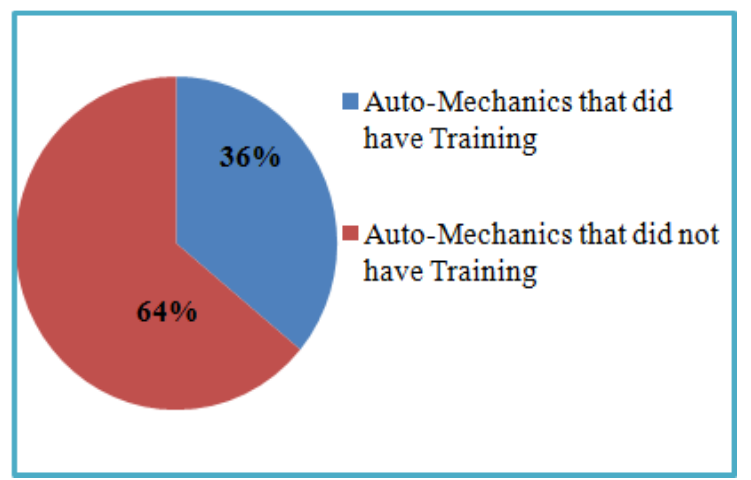

Fig. 7. Training of Auto-mechanics

After graduating as junior mechanic from post-secondary training center or apprenticeship training program and entering the job market as junior or senior mechanic, it is important to continue to retrain to keep up with technological advances. As illustrated in fig.7, over $64 \%$ of the auto-mechanics do not see the need for any training and re-training. From observations, they seem to be content with their current inadequate skills levels just because they have the capability to maintain some vehicles, especially the old models of vehicles in the country. Occasionally, the few well endowed garages in the country such as Mechanical LIoy, Toyota Ghana, Silver Star, Japan Motors and others do well to organize in-service training in the form of conferences, workshops, seminars, symposia etc. for the micro, small and medium garages in the country. Other organizations such as, Ghana Regional Appropriate Technology Industrial Service-GRATIS Foundation, Intermediary Technology Transfer Unit-ITTU, National Board for Small-Scale Industries-NBSSI, Council for Scientific and Industrial Research-CSIR, and so on also endeavor to collaborate with these micro and small garages in the areas of technology development and transfer, vocational and apprentice training [11]. This is to enable the less endowed garages in the country to update and upgrade their technical competencies and to keep abreast with current best auto repair practices. Unfortunately, however, an informal interview with the micro and small scale garages in the country reveals that they hardly take advantage of these training programs to upgrade their skills due to lack of time and sometimes the minimum training cost involved.

Moreover, to become proficient in a complex specialty such as automotive air-conditioning, electronic engine systems, transmission repairs as well as other similar specialty repairs might require another year or two of training or on the job experience. On-going training including classes at manufacturers' facilities to learn new technologies is common and technicians are expected to keep up with ever-changing systems through reading and on-the-job practice [16]. Worldwide, there are many workshops available to professional auto mechanics. Because the technology associated with the field is constantly improving, many workshops, symposia, conferences etc. are designed to address these advances and they are offered at local colleges, conference centers, or auto repair garages. Again, there are also training and in-service training programs available on the internet to enable mechanics to become proficient in their auto repair practices [17].

Indeed, education and training is a lifelong process. The mechanics in this country should see re-training programs as fundamental to their sustenance and survival in the current auto repair industry. They should therefore take advantage of the training programs offered by the aforementioned organizations in the country to continually polish their skills.

\section{G. Environment, Health and Safety in Garages}

As pointed out earlier, most of the micro and small garages in the country are operating in the informal sector and receiving limited training. Hence, the level of awareness and standards of health and safety achieved within the garages are substantially lower than would be expected in a modern vehicle repair garage environment. This is an issue not only in terms of injuries and damage to the health of auto mechanics, but also in that it discourages formal-sector local medium and large scale garages such as Silver Star, Holy Motors, Toyota Ghana etc. from placing contracts with the micro and small garages in the country. While it is immediately apparent that health and safety standards in these micro and small garages are low, there is little data currently available to identify the highest priority areas of risk and the most cost-effective means of risk reduction. Many of the environmental issues relate to the context and infrastructure of the site. Oil, for example, is allowed to drain into the ground; fumes are released unfiltered into the atmosphere; no proper methods of storing waste oils and so on.

Also, the mechanics of these garages are potentially exposed to a variety of chemical and physical hazards. Chemical hazards may include volatile organics from paints, fillers and solvents; diisocyanates, polyisocyanates, and hexavalent chromium from spray painting operations; silica from sandblasting operations; dusts from sanding; and metal fumes from welding and cutting. Physical hazards include repetitive stress and other ergonomic injuries, noise, lifts, cutting tools, and oil and grease on walking surfaces. This actually serves as a disincentive for both mechanics and customers. Also, from observations, the mechanics in the less endowed local garages in the country frequently work with dirty and greasy parts, and in awkward positions. They often lift heavy parts and tools and in the process experience minor cuts, burns and bruises [18].

To work in accordance with the rules and regulations pertaining to auto maintenance practices in the country, and also to ensure safety of auto mechanics and help save the environment, it is important that the garages in the country devise safe systems of work to ensure the safety of workers and the occupants of vehicles being recovered/repaired. The environmental protection agency (EPA), the Ministry of Environment, Science and Technology (MEST), the Ministry of Trade and Industry and other similar institutions should come up with by-laws to regulate the activities of the local garages. They should also intensify their visits and inspections to the local garages to ensure that the latter observe safe environmental practices in their vehicle repair and 
maintenance procedures.

\section{Conclusion}

In this paper, the modern auto repair practices in the Ghanaian auto vehicle repair garages have been discussed. Automobile vehicle repair garages help to maintain the vehicles on the roads. Currently, most of the micro, small and medium scale vehicle repair garages in the country are faced with numerous challenges including: Low capital and infrastructure base, inability to acquire and use modern vehicle diagnostic equipments and tools, low educational levels, lack of training and re-training, inability to use computers and internet facilities for vehicle repairs, inability to identify parts of modern vehicle engines by their correct technical names and functions, low income levels, threats of ejection from landlords/owners, lack of access to bank loans, and above all lost of customers and eminent closures. To help forestall the collapse of these garages in the country, the training institutions such as the universities and the polytechnics, the Gratis Foundation, the NBSSI and other similar organizations should organize in-service training for the mechanics to enable them update and upgrade their technical competencies and computer skills. The government, the banks as well as other private organizations should assist to re-tool and equip the small and medium garages in the country with modern equipments, especially the electronic vehicle diagnostic equipments such as oscilloscopes, scanners, diagnostic code scanners, computerized diagnostic testers, portable data link (PDL), exhaust gas analyzers and so no. The EPA, the Ministry of Environment, Science and Technology, and the Ministry of Trade and Industry should visit the garages regularly to educate them on safety and safe environmental practices. The government should come up with by-laws which will seek to forester harmonious relationships between landlords and garage owners. The landlords should be willing to allow the garage owners to operate their garages for longer number of years or even eventually sell the lands to the garage owners. This will provide the impetus to enable garage owners to invest more capital resources, grow the garages, operate as profit making establishments and help reduce unemployment rates in the country.

\section{References}

[1] D. Agyapong, "Micro, Small, Medium and Large Enterprises' Activities, Income Level and Poverty Reduction in Ghana- A synthesis of Related literature", International Journal of Business and Management, Vol. 5, 2010, pp. 198-199.

[2] A.O. Akinola, "Parts Standardization in the Motor Industry". B. Eng. Thesis, Dept. of Mechanical Engineering Federal Univ. of Technology, Akure, Nigeria, 1995.
[3] B. Akinola and T. Ogedenge, "Basic Automobile Technology", Olajuyin Printers, Akure, Nigeria, 2005.

[4] Modern Riders, 2014, Factsheet: How Modern Cars Engines are Different. [Online]. Available at http://www.modernrides.com/how-modern-car-engines-are-dif ferent. [Accessed on 20th August, 2014].

[5] Chron, 2014, Factsheet: What Kind of Equipment Does an Auto Mechanic Use? [Online]. Available at http://www.work.chron/kind-equipment-auto-mechanic-use-2 5000.html. [Accessed on 30th August, 2014].

[6] J. POWELL, "Survey of Engineering Manufacturing Industries in Ghana. Technology and Enterprise Development Project". A Report for DFID, London, UK., 1995.

[7] Industrial Areas in Ghana, 2014, Factsheet: Map for Industrial Areas in Ghana. [Online]. Available at https://www.google.com.gh [Accessed on 30th August, 2014].

[8] Automotive Body and Related Repairers, 2014, Factsheet: Career Information: Available at https://www.collegegrad.com/careers/insta06 [Accessed on 20th August, 2014]

[9] Automotive Service Technicians and Mechanics, 2014, Factsheet: Career Information: Available at https://www/collegegrad.com/careers/insta08 [Accessed on 20th August, 2014]

[10] Chron, 2014, Factsheet: What kind of Equipment does an auto mechanic use: Available at http://www. work.chron.com/kind-eqiuipment-auto-mechanic-use-25000.h tml. [Accessed on 10th August, 2014].

[11] T. Jaarsma, Car repair in the Suame Magazine, thesis submitted to KNUST, 2009, pp. 23-74.

[12] Kumsi Center, 2003, Factsheet: Suame Magazine Fihankra Project: Available at http://www.kumasicenter.wordpress.com/2012/10/17/suame-m agazine-fihankra-project/ [Accessed on 20th July, 2014].

[13] Car Diagnostics-FAQs, 2013, Factsheet: Hallmark Volvo: Available at http://www.hallmarkvolvo.com/car-diagnostics-fags/Hallmark

[14] J. Jones, J. Burdess, J.N. Fawcett, Vehicle Electronic Systems and Faults Diagnosis, Routledge, 2013, pp. 20-50.

[15] How to Open an Auto Repair Shop, 2014, Factsheet, Appointments: Available at www.appoitment-plus.com/articles/how-to-open-an-auto-repai r-shop.php

[16] J. M. Mutmansky, R.V. Ramani, 11th US/North American Mine Ventilation Symposium, CRC Press, 2006, pp. 89-110.

[17] Providing Hands on Automotive Care, 2013, Factsheet: Diesel Mechanic, [AcademiCINFO], Available at http://www.academicinfo.net/online-course/diesel-mechanic.

[18] E. J. Duffy, and R. Scharff, "Autobody Repair Technology”, Cengage Learning, 2003, pp. 234- 250. 